\title{
Ultrasound Guided Vascular Access in The Neonatal Intensive Care Unit: A Nationwide Survey
}

Ignacio Oulego-Erroz ( $\sim$ ignacio.oulego@gmail.com )

Complejo Asistencial Universitario de Leon https://orcid.org/0000-0002-9653-954X

Almudena Alonso-Ojembarrena

Hospital Universitario Puerta del Mar

Victoria Aldecoa-Bilbao

Hospital Clinic de Barcelona

Maria Carmen Bravo

La Paz University Hospital: Hospital Universitario La Paz

Jon Montero-Gato

Basurto Hospital: Hospital de Basurto

Rocio Mosqueda-Peña

Hospital Universitario 12 de Octubre

Antonio Rodríguez-Núñez

University Hospital of Santiago de Compostela: Complejo Hospitalario Universitario de Santiago de Compostela

\section{Research Article}

Keywords: Neonatal Intensive Care Unit, Ultrasound guided vascular access, Point of care ultrasound, Training, Implementation, Central Venous Catheter

Posted Date: January 4th, 2022

DOI: https://doi.org/10.21203/rs.3.rs-1182941/v1

License: (1) This work is licensed under a Creative Commons Attribution 4.0 International License. Read Full License

Version of Record: A version of this preprint was published at European Journal of Pediatrics on March 17th, 2022. See the published version at https://doi.org/10.1007/s00431-022-04400-3. 


\section{Abstract}

Ultrasound guided percutaneous vascular access (USG-PVA) is recommended by international practice guidelines but information regarding its use in the neonatal intensive care unit (NICU) is lacking. Our objective was to assess neonatologist's perceptions and current implementation of USG-PVA in Spain. This was a nationwide online survey. The survey was composed of 37 questions divided in 4 domains: 1) neonatologist's background, 2) NICU characteristics, 3) personal perspectives about USG-PVA and clinical experience in USGPVA. One hundred and eighty survey responses from 59 NICUs (62\% of Spanish NICUs) were analyzed. Most neonatologist (81\%) perceive that competence in USG-PVA is indispensable or very useful in clinical practice. However, 64 (35.5\%) have never used USG-PVA in real patients. Among neonatologists with some experience in USG-PVA most perform less than 5 procedures per year ( $59 \%$ in venous access and $80 \%$ in arterial access) and a $38 \%$ and $60 \%$ have never used USG for venous and arterial access respectively in very low birth weight infants (VLBWI). Spanish neonatologists report that residents/fellows training in USG-PVA is absent (52.2\%) or unstructured (32\%) in their units. The lack of adequate training is identified by a $60 \%$ of neonatologists as the most important barrier for implementation of USG-PVA and $87 \%$ would recommend that future neonatologists receive formal training. In conclusion, Spanish neonatologists perceive that USGPVA is important in clinical practice but, currently these techniques are largely underused. Our results indicate that specific training in USG-PVA should be implemented in the NICU.

\section{What'S Known}

-Ultrasound guided vascular access is recommended as the preferred method for central venous access and arterial line placement in children and adults

-The degree of current implementation of ultrasound for vascular access in the NICU and the perceptions of neonatologist about its use are largely unknown.

\section{WHAT'S NEW}

-Most neonatologists consider that competence in ultrasound guided vascular access is an indispensable aid for clinical practice.

-However, most neonatologists are not adequately trained in ultrasound guided vascular access and the technique is largely underused.

\section{Introduction}

Percutaneous vascular access (PVA) in children is more challenging than in the adult patient due to several factors such as vessel size, anatomical variations, lack of collaboration or need for sedation. $[1,2]$ The neonatal population represents a very particular subset where vascular access is highly problematic, especially in the preterm infant and there is a lack of high level evidence to guide vascular access practices [3-5]. Most preterm and sick neonates require a central venous access. Umbilical vessels are the first choice for central access during the first days of life.[6] Thereafter, most patients receive a peripherally inserted central catheter (PICC) like the epicutaneous-cava catheter (ECC).[7] While such devices suffice for routine care in most instances, the sickest patients who need high intensity care benefit from large-bore central venous catheters (CVC) and arterial lines. Placement of a CVC in neonates has been traditionally considered a high-risk procedure. However, there are several studies that confirm that USG-CVC is feasible and safe in neonates and even preterm infants.[8-11] Recent clinical practice guidelines on point of care ultrasound (POCUS) have been released by the European Society of Pediatric and Neonatal Intensive Care (ESPNIC)[12]. In these guidelines the use of USG is recommended for placement of internal jugular vein (IJV) catheters (strong agreement, quality of evidence A) and it is considered helpful for insertion of other CVCs, peripherally inserted central catheters (PICC), arterial lines as well as for the assessment of central venous catheter (CVC) tip location (strong agreement, quality of evidence B). Despite of the paramount clinical relevance of vascular access in neonates, there is a complete lack of data regarding the current implementation of USG-PVA in the NICU.

With the hypothesis that USG-PVA is underused, the objective of the present study was to assess current practice regarding USG-PVA in the Neonatal Unit as well as to analyze the perceptions of Spanish neonatologist regarding the clinical utility, risks and barriers for implementation of these techniques in their current practice.

\section{Materials And Methods}

This was an online-survey based study promoted by the Working Group on Ultrasound (WG-US) of the Spanish Society of Neonatology (SENeo). The WG designed the study according to the CHERRIES and CROSS guidelines for survey studies. $[13,14]$ The target population 
were active Spanish neonatologists who were identified from the affiliate registry of the SENeo. One expert in USG-PVA from the WG and one additional expert not involved in the WG-US activities developed the first draft of the survey. The initial proposal included 46 questions divided in 4 domains: 1) neonatologist's data and background, 2) NICU characteristics, 3) clinical experience in USG-PVA and 4) perceptions about USG-PVA). This initial proposal was reviewed by a panel of 6 neonatologist from the WG-US with interest and expertise in USG-PVA. The WG members discussed the appropriateness of every question. Additionally, each member of the panel was allowed to add and remove up to three questions. Each question was assigned a priority (high, medium, low) based on rating of the content validity and reliability using a predefined color-coded Likert scale.[15] Four rounds of corrections were needed until a consensus was reached. The final survey consisted in 37 questions (Appendix 1 in supplementary content) including an adaptative question to reduce complexity (only those responders who reported some experience in USG-PVA were allowed to answer questions in the domain 3). No personal information from participants apart from the email address was recorded. Only one response per participant was allowed by requesting and checking email address with each response. Incomplete surveys were discarded from the analysis.

The survey was uploaded to Google Forms ${ }^{\circledR}$. The survey was headed by a brief text with a description of the research group and the study objectives. The questionnaire was arranged in four screen pages and estimated time for completion was 15 minutes. Responders were allowed to review and change responses ("back-button") before final submission.

The survey link was mailed to the 756 affiliates of the SENeo on the 15th of September 2021. The survey was advertised on the SENeo website and during the virtual National Congress of the SENeo that took place on the 27-28th October of 2021. Up to 5 reminder e-mails were sent during a three-month period before closing recruitment.

\section{Statistical analysis}

Numerical data are summarized as mean (standard deviation). Qualitative data are summarized as number (percentage). An analysis of factors associated with current use of USG-PVA in real practice was performed using multivariate logistic regression. Covariates were chosen based on author's previous knowledge and a literature review and included operator's age, operator's year working in Neonatology, NICU complexity, working on a teaching NICU, working on a mixed (pediatric and neonatal) unit, previous training in USG-PVA and years performing USG-PVA in clinical practice. Only variables with a $p<0.1$ in univariate analysis were introduced in the multivariate models. We investigated factors associated with the use of USG-PVA (all responses; $n=180$ ) and then factors predicting the number of USG-CVC procedures $(n=116)$ per year. SPSS v25 software was used for the analysis.

\section{Results}

One hundred and ninety-three survey responses were received (response rate $25 \%$ ). Thirteen surveys were discarded because incomplete data $(n=8)$ or duplicates $(n=5)$. Finally, a total of 180 surveys coming from 59 NICUs ( $62 \%$ of Spanish NICUs) were included in the analysis. Data related to neonatologist's background and NICU characteristics are summarized in Table 1. The neonatologist's mean (SD) age and years of clinical practice were 41 (7.6) and 12.6 (7.4) years respectively. Most neonatologist worked in teaching units (66.7\%) but reported that training of residents/fellows in USG-PVA was absent (52.2\%) or occasional (32.2\%) in their units. Sixty-four (35.6\%) of the responders had no experience placing USG-PVA in real patients. These practitioners were significantly older ( $<<0.001)$, have received previous training in POCUS $(p<0.001)$ or USG-PVA $(p<0.001)$ less frequently and worked in lower-complexity $(p<0.001)$ and smaller NICUs $(p<0.001)$ compared to those who have performed USG-PVA in clinical practice. Nearly a half of responders (51.1\%) reported that less than $25 \%$ of the attending neonatologists perform USG-PVA in their units and only a $13.3 \%$ reported that more than> $75 \%$ of the staff perform these techniques regularly. 
Table 1

Neonatologist's basic data and background and NICU characteristics according to experience in USG-PVA

\begin{tabular}{|c|c|c|c|c|}
\hline & $\begin{array}{l}\text { All } \\
(n=180)\end{array}$ & $\begin{array}{l}\text { No experience in } \\
\text { USG-PVA }(n=64)\end{array}$ & $\begin{array}{l}\text { Some experience in } \\
\text { USG-PVA }(n=116)\end{array}$ & $\mathbf{p}$ \\
\hline \multicolumn{5}{|l|}{ Neonatologist`s basic data and background } \\
\hline Age & $41(7.6)$ & $45.7(7.6)$ & $39.4(6.7)$ & $<0.001$ \\
\hline Years of clinical practice in Neonatology & $\begin{array}{l}12.6 \\
(7.4)\end{array}$ & $16.6(7.6)$ & $10.3(6.4)$ & $<0.001$ \\
\hline Full time dedication as neonatologist & $\begin{array}{l}116 \\
(64.4 \%)\end{array}$ & $32(50.8 \%)$ & $84(72.4 \%)$ & 0.004 \\
\hline $\begin{array}{l}\text { POCUS training during residency } \\
\text {-No training } \\
\text {-Some training }\end{array}$ & $\begin{array}{l}128 \\
(71.1 \%) \\
52 \\
(28.9 \%)\end{array}$ & $\begin{array}{l}58(90.6 \%) \\
6(9.4 \%)\end{array}$ & $\begin{array}{l}70(60.3 \%) \\
46(39.7 \%)\end{array}$ & $<0.001$ \\
\hline $\begin{array}{l}\text { Training in USG-PVA } \\
\text {-No training } \\
\text {-Unstructured training }\end{array}$ & $\begin{array}{l}46 \\
(25.5 \%) \\
66 \\
(36.7 \%)\end{array}$ & $\begin{array}{l}44(68.7 \%) \\
10(15.6 \%) \\
10(15.6 \%)\end{array}$ & $\begin{array}{l}2(1.7 \%) \\
56(48.3) \\
58(50 \%)\end{array}$ & $<0.001$ \\
\hline -Structured training & $\begin{array}{l}68 \\
(37.8 \%)\end{array}$ & & & \\
\hline \multicolumn{5}{|l|}{ NICU characteristics } \\
\hline Mixed NICU/PICU & $\begin{array}{l}36 \\
(20 \%)\end{array}$ & $10(15.6 \%)$ & $26(22.4 \%)$ & 0.276 \\
\hline NICU level according to official denomination in Spain & $\begin{array}{l}50 \\
(27.8 \%)\end{array}$ & $4(6.2 \%)$ & $46(39.6 \%)$ & $<0.001$ \\
\hline$-I I I c$ & & $34(53.1 \%)$ & $54(46.5 \%)$ & \\
\hline$-|l l| b$ & $(48.9 \%)$ & $26(40.6 \%)$ & $16(13.8 \%$ & \\
\hline -Other (IIIa, IIb,IIc, I) & $\begin{array}{l}42 \\
23.3 \%)\end{array}$ & & & \\
\hline High complexity NICU * & $\begin{array}{l}44 \\
(24.4 \%)\end{array}$ & $4(6.2 \%)$ & $40(34.5 \%)$ & $<0.001$ \\
\hline Number of NICU beds & $\begin{array}{l}109 \\
(60.5 \%)\end{array}$ & $51(79.6 \%)$ & $58(50 \%)$ & $<0.001$ \\
\hline$-\leq 10$ & & $10(15.6 \%)$ & $36(31 \%)$ & \\
\hline-11 to 20 & $(25.5 \%)$ & $2(3.1 \%)$ & $22(19 \%)$ & \\
\hline$\rightarrow 20$ & $\begin{array}{l}24 \\
13.3 \%\end{array}$ & & & \\
\hline Number of attending neonatologist in your hospital & $9.4(5)$ & $6.7(3.5)$ & $10.9(5)$ & $<0.001$ \\
\hline Teaching NICU & $\begin{array}{l}120 \\
(66.7 \%)\end{array}$ & $34(53.1 \%)$ & $86(74.1 \%)$ & 0.004 \\
\hline Training of residents in USG-PVA & $\begin{array}{l}94 \\
(52.2 \%)\end{array}$ & $44(68.7 \%)$ & $5043.1 \%)$ & 0.003 \\
\hline -No training & 58 & $14(21.9 \%)$ & $42(36.2 \%)$ & \\
\hline -Occasional training (not structured/incomplete adherence) & $(32.2 \%)$ & $6(9.4 \%)$ & $24(20.7 \%)$ & \\
\hline -Formal training program with full or near full adherence & $\begin{array}{l}30 \\
(16.7 \%)\end{array}$ & & & \\
\hline
\end{tabular}

*High complexity NICU is arbitrary defined as that unit providing ECMO and cardiac surgery. High complexity NICU is defined as that providing cardiac surgery and ECMO. CVC: central venous catheter; NICU: neonatal intensive care unit; PICU: pediatric intensive care unit; POCUS: point of care ultrasound; PVA: percutaneous vascular access; USG: ultrasound guided; VLBWI: very low birth weight infants. 


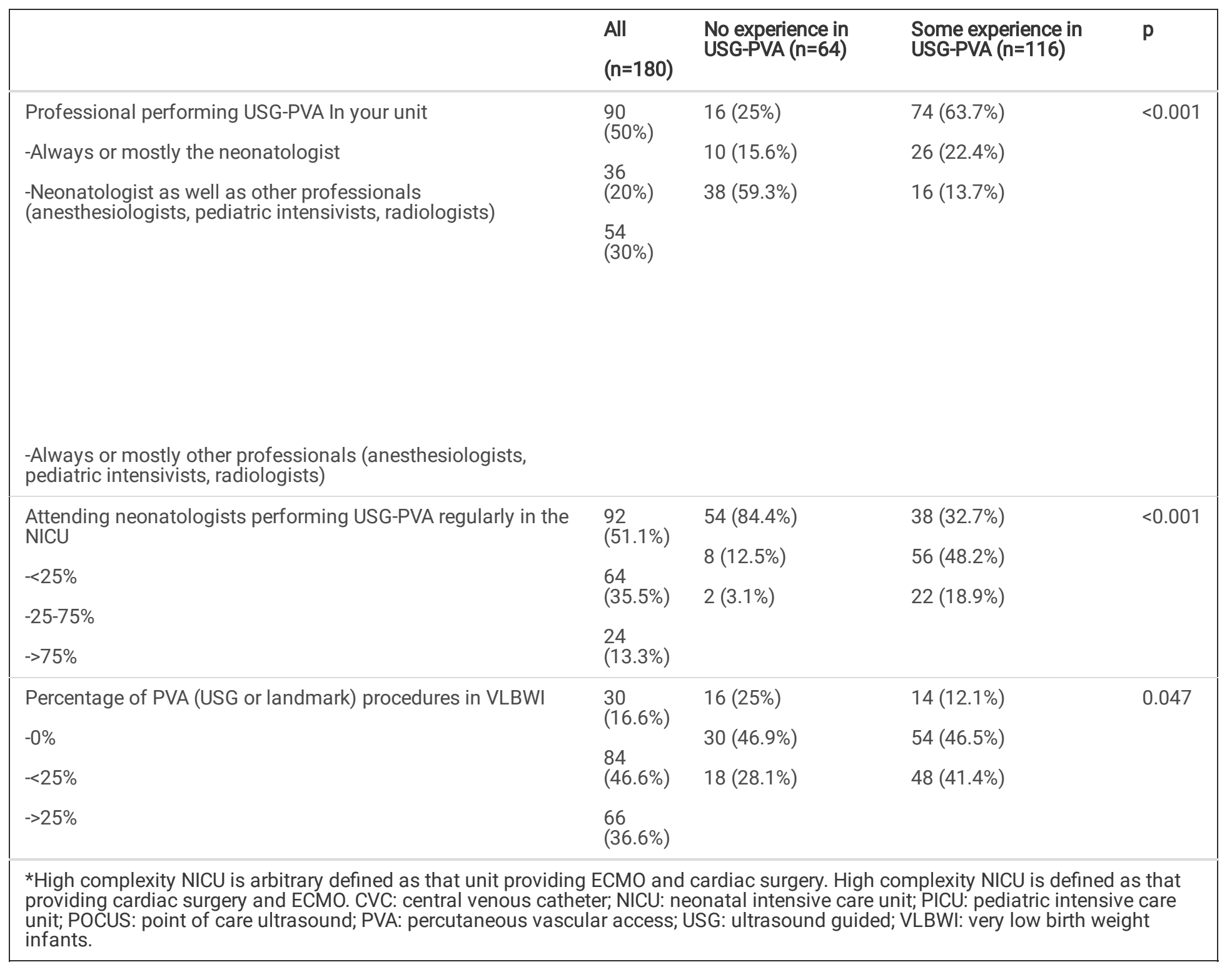

Among those neonatologists ( $n=116)$ with some clinical experience in USG-PVA (Table 2) a 62\% perform less than 5 USG-CVC insertions per year and a $38 \%$ have never used this technique in VLBWI (Figure 1A). Most neonatologist report that the main indication for USG-CVC insertion is as a rescue procedure after exhausted peripheral vein access (53.4\%) followed by acute hemodynamic instability (27.5\%). Only a minority perform this technique electively $(18.9 \%)$ for administration of multiple drugs, blood draws or in high-risk surgical patients. The femoral vein (FV) is the preferred insertion site for most neonatologist (62\%) followed by the internal jugular vein (IJV) in $32.7 \%$. The use of supraclavicular brachiocephalic (BCV)/subclavian vein cannulation was infrequent (5.1\%). Regarding arterial lines most neonatologists (79\%) report that they perform less than 5 procedures per year and a $60 \%$ have not inserted any USG arterial line in VLBWI (Figure 1B). The main indication for USG arterial line placement is invasive blood pressure monitoring (70.7\%). The preferred insertion site for most neonatologist is the femoral artery $(62 \%)$ followed by the radial artery (31\%). 
Table 2

Neonatologist's personal experience using ultrasound guider percutaneous vascular access according to NICU complexity

\begin{tabular}{|c|c|c|c|c|}
\hline & $\begin{array}{l}\text { ALL } \\
(n=116)\end{array}$ & $\begin{array}{l}\mathrm{HC}-\mathrm{NICU} \\
(\mathrm{n}=40)\end{array}$ & $\begin{array}{l}\text { LC-NICU } \\
(n=76)\end{array}$ & $p$ \\
\hline $\begin{array}{l}\text { Years performing USG-PVA procedures in clinical practice } \\
-<2 \text { years }\end{array}$ & $\begin{array}{l}40 \\
(34.5 \%) \\
36(31 \%) \\
40 \\
(34.5 \%)\end{array}$ & 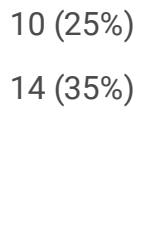 & 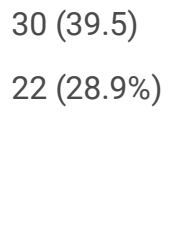 & 0.265 \\
\hline $\begin{array}{l}-2 \text { to } 5 \text { years } \\
->5 \text { years }\end{array}$ & & $16(40 \%)$ & 24 (31.6\%) & \\
\hline $\begin{array}{l}\text { When you place a PVA, do you use US? } \\
\text {-Always } \\
\text {-Sometimes }\end{array}$ & $\begin{array}{l}90 \\
(77.6 \%) \\
14 \\
(12.1 \%)\end{array}$ & $\begin{array}{l}32(80 \%) \\
6(15 \%) \\
2(5 \%)\end{array}$ & $\begin{array}{l}58(76.3 \%) \\
8(10.5 \%) \\
10(13.1 \%)\end{array}$ & 0.339 \\
\hline -Never & $\begin{array}{l}12 \\
(10.3 \%)\end{array}$ & & & \\
\hline $\begin{array}{l}\text { Number of USG central lines per year } \\
-<5 \text { CVC per year } \\
->5 \text { CVC per year }\end{array}$ & $\begin{array}{l}72 \\
(62.1 \%) \\
44 \\
(37.9 \%)\end{array}$ & $\begin{array}{l}16(40 \%) \\
24(60 \%)\end{array}$ & $\begin{array}{l}56(7.4 \%) \\
20(26.3 \%)\end{array}$ & $<0.001$ \\
\hline $\begin{array}{l}\text { Percentage of CVC placements in VLBW infants } \\
-<25 \% \\
->25 \%\end{array}$ & $\begin{array}{l}82 \\
(70.7 \%) \\
34 \\
(29.3 \%)\end{array}$ & $\begin{array}{l}26(65 \%) \\
14(35 \%)\end{array}$ & $\begin{array}{l}56(73.7 \%) \\
20(26.3 \%)\end{array}$ & 0.329 \\
\hline $\begin{array}{l}\text { Main Indication for USG-PVA of CVC } \\
\text {-Rescue procedure after exhausted peripheral access } \\
\text {-Hemodynamic instability }\end{array}$ & $\begin{array}{l}62 \\
(53.4 \%) \\
32 \\
(27.6 \%)\end{array}$ & $\begin{array}{l}24(60 \%) \\
12(30 \%) \\
4(10 \%)\end{array}$ & $\begin{array}{l}38(50 \%) \\
20(26.3 \%) \\
18(23.7 \%)\end{array}$ & 0.201 \\
\hline $\begin{array}{l}\text {-Elective insertion (multiple drugs, need for blood draws, high risk surgical } \\
\text { patients) }\end{array}$ & 22 & & & \\
\hline $\begin{array}{l}\text { Preferred USG-CVC insertion site } \\
\text {-Internal jugular vein } \\
\text {-Brachiocephalic/subclavian vein (supraclavicular approach) } \\
\text {-Femoral vein }\end{array}$ & $\begin{array}{l}38 \\
(32.8 \%) \\
6(5.1 \%) \\
72 \\
(62.1 \%)\end{array}$ & $\begin{array}{l}10(25 \%) \\
2(5 \%) \\
28(70 \%)\end{array}$ & $\begin{array}{l}28(36.7 \%) \\
4(5.3 \%) \\
44(57.9 \%) \\
0(0 \%)\end{array}$ & 0.418 \\
\hline -Other & $0(0 \%)$ & & & \\
\hline $\begin{array}{l}\text { Number of arterial line placements per year } \\
-<5 \text { arterial lines per year } \\
->5 \text { arterial lines per year }\end{array}$ & $\begin{array}{l}92 \\
(79.3 \%) \\
24 \\
(20.7 \%)\end{array}$ & $14(35 \%)$ & 66 (86.8\%) & 0.006 \\
\hline
\end{tabular}

Only responses from neonatologists with some experience using USG-PVA are included in this description. *These data are referred to the whole sample $(n=180)$. High complexity NICU is defined as that providing cardiac surgery and ECMO. CVC: central venous catheter; ECHO: echocardiography; NICU: neonatal intensive care unit; PVA: percutaneous vascular access; USG: ultrasound guided; US: ultrasound, UVC: umbilical vein catheter; VLBWI: very low birth weight infants. 


\begin{tabular}{|c|c|c|c|c|}
\hline & $\begin{array}{l}\text { ALL } \\
(n=116)\end{array}$ & $\begin{array}{l}\mathrm{HC}-\mathrm{NICU} \\
(\mathrm{n}=40)\end{array}$ & $\begin{array}{l}\text { LC-NICU } \\
(n=76)\end{array}$ & p \\
\hline \multirow{3}{*}{$\begin{array}{l}\text { Percentage of arterial line placements in VLBWI } \\
-<25 \% \\
->25 \%\end{array}$} & \multirow{2}{*}{$\begin{array}{l}108 \\
(93.1 \%)\end{array}$} & $34(85 \%)$ & $74(97.4 \%)$ & \multirow[t]{3}{*}{0.012} \\
\hline & & $6(15 \%)$ & $2(2.6 \%)$ & \\
\hline & $8(6.9 \%)$ & & & \\
\hline Main indication for arterial line placement & \multirow{2}{*}{$\begin{array}{l}82 \\
(70.6 \%)\end{array}$} & $28(70 \%)$ & $54(71 \%)$ & \multirow[t]{3}{*}{0.234} \\
\hline -Invasive blood pressure in hemodynamically instability & & $8(20 \%)$ & $8(10.5 \%)$ & \\
\hline -Frequent blood gas sampling & $\begin{array}{l}16 \\
(13.4 \%)\end{array}$ & $4(10 \%)$ & $14(18.4 \%)$ & \\
\hline -Elective in high-risk infants/other indications & \multicolumn{2}{|l|}{$\begin{array}{l}18 \\
(15.5 \%)\end{array}$} & & \\
\hline Preferred site for arterial line insertion & \multirow{2}{*}{$\begin{array}{l}72 \\
(62.1 \%)\end{array}$} & $26(65 \%)$ & $46(60.5 \%)$ & \multirow[t]{4}{*}{0.809} \\
\hline -Femoral artery & & $12(30 \%)$ & $24(31.6 \%)$ & \\
\hline -Radial artery & \multirow{2}{*}{$8(6.9 \%)$} & $2(5 \%)$ & $6(7.9 \%)$ & \\
\hline -uther (axillary, numeral, etc.) & & & & \\
\hline Do you use US/ECHO to check central line tip position?* & \multirow{2}{*}{$\begin{array}{l}80 \\
(44.4 \%)\end{array}$} & $20(45.4 \%)$ & $60(44.1 \%)$ & \multirow[t]{5}{*}{0.527} \\
\hline -No & & $18(40.1 \%)$ & $54(39.7 \%)$ & \\
\hline -Yes, for any CVC & \multirow{2}{*}{$\begin{array}{l}24 \\
(13.3 \%)\end{array}$} & $4(9 \%)$ & $20(14.7 \%)$ & \\
\hline -Yes, just for UVC & & $2(4.5)$ & $2(1.5 \%)$ & \\
\hline -Yes, just for those CVC inserted though extremities/neck & $4(2.2 \%)$ & & & \\
\hline \multirow{2}{*}{$\begin{array}{l}\text { Exclusive use of US/ECHO to check central line tip position (without confirmation } \\
\text { with chest radiography)* }\end{array}$} & \multirow{2}{*}{$\begin{array}{l}84 \\
(46.6 \%)\end{array}$} & $20(45.4 \%)$ & $64(47.8 \%)$ & \multirow[t]{6}{*}{0.181} \\
\hline & & $20(45.4 \%)$ & $46(33.8 \%)$ & \\
\hline$-0 \%$ of central lines & $\begin{array}{l}66 \\
(36.7 \%)\end{array}$ & $2(4.6 \%)$ & $22(16.2 \%)$ & \\
\hline$-<25 \%$ of central lines & \multirow{2}{*}{$\begin{array}{l}24 \\
(13.3 \%)\end{array}$} & $2(46 \%)$ & $4(29 \%)$ & \\
\hline$-25-75 \%$ of central lines & & $2(7.00)$ & & \\
\hline ->75\% of central lines & \multicolumn{2}{|l|}{$6(3.3 \%)$} & & \\
\hline $\begin{array}{l}\text { Only responses from neonatologists with some experience using USG-PVA are in } \\
\text { the whole sample }(n=180) \text {. High complexity NICU is defined as that providing car } \\
\text { catheter; ECHO: echocardiography; NICU: neonatal intensive care unit; PVA: percu } \\
\text { US: ultrasound, UVC: umbilical vein catheter; VLBWl: very low birth weight infants }\end{array}$ & $\begin{array}{l}\text { ded in this } \\
\text { c surgery } \\
\text { eous vas }\end{array}$ & $\begin{array}{l}\text { escription. } \\
\text { d ECMO. CV } \\
\text { ar access; U }\end{array}$ & $\begin{array}{l}\text { se data are } \\
\text { entral venou } \\
\text { ultrasound }\end{array}$ & $\begin{array}{l}\text { erred to } \\
\text { ided; }\end{array}$ \\
\hline
\end{tabular}

Regarding personal perceptions about USG-PVA (Table 3), most neonatologists believe that attaining competence in these techniques is indispensable (30\%) or very useful $(56.7 \%)$ for their practice and would recommend that current Neonatology trainees be taught USG-PVA as an indispensable (40.6\%) or very useful skill (46.1\%). A $47.8 \%$ of the neonatologist believe that reduced vessel size is the main factor that makes PVA difficult. A $60 \%$ of the responders identify the lack of training as the main factor limiting the implantation of USG-PVA over other factors such as technical difficulty (18.9\%) or lack of adapted equipment for neonates (16.7\%). When asked about different locations for insertion of USG central lines, only a 33\% identified the BCV as the largest central vein amenable for percutaneous puncture and only a $15.6 \%$ would consider supraclavicular cannulation of the BCV as the optimal USG technique for central venous access in neonates. A significant proportion (32.2\%) believe that FV is larger than IJV or BCV. Most neonatologists consider that the risk/benefit balance is favorable to conventional ECCs compared to PVA of central veins, especially in preterm infants. 
Table 3

Neonatologist's perceptions about ultrasound guided percutaneous vascular access in the neonatal intensive care unit

\section{Perceptions about USG-PVA in the neonatal intensive care unit}

How do you rate the importance of being competent in USG-PVA in your daily practice?

$54(30 \%)$

-Indispensable

102

-Very useful and necessary

(56.7\%)

-Useful but not a priority

-Secondary or residual

-Useless or even counterproductive

Would you recommend that current Neonatology residents/fellows be trained in ultrasound guided percutaneous

vascular access skills?

-Indispensable skill

-Very useful skill

-Useful but not mandatory skill

-Secondary skill during training

-Not useful or even counterproductive if it rests time for other more important aspects of training.

Main factor limiting PVA in neonates

$0(0 \%)$

-The size of the vessels

-Easy collapse of the vessel

-Lack of adequate transducers

-Lack of physical space (eg: incubator) during cannulation

-I don't' know

Main factor limiting the use of USG-PVA in Neonatology

-Lack of adequate training of the neonatologist

-High technical difficulty of the procedure

-Lack of adequate equipment for neonates (ultrasound, probes etc.)

-The high risks of the procedure

How many USG-PVA procedures are needed to attain competence

$-5-10$

$-10-20$

$-20-50$

$->50$

Which of the following is, in your opinion, the largest central vein amenable for PVA?

-Brachiocephalic vein

-Femoral vein

-Internal jugular vein

-Subclavian vein very low birth weight infants. 


\section{Perceptions about USG-PVA in the neonatal intensive care unit}

Optimal USG-PVA site location for central line placement in neonates

-Internal jugular vein

-Femoral vein

-Brachiocephalic vein (supraclavicular in plane insertion)

-l don't know

-Always or nearly always favorable to ECC

-It depends on the patient's characteristics and operator's experience

-Always or nearly always favorable to USG central line

Risk/benefit balance of USG central line vs ECC in a VLBWI

-Always or nearly always favorable to ECC

-It depends on the patient's characteristics and operator's experience

CVC: central venous catheter; ECC: epicutaneous-cava catheter; PVA: percutaneous vascular access; USG: ultrasound guided; VLBWI: very low birth weight infants.

In multivariate logistic regression lower operator age and previous training in the technique were associated with current use of USG-PVA in clinical practice (supplementary table 1). However, when factors associated with a higher number of USG central venous access performed per year were assessed, we found that the main predictors were longer clinical experience using USG-PVA and higher operator's age (supplementary table 2). The relationship between operator's age and use of USG-PVA is shown in figure 2.

\section{Discussion}

Effective and safe vascular access is a critical component of care of sick neonates. USG-PVA is recommended for insertion of central venous catheters and arterial lines.[12, 16, 17] There have been several studies assessing the implementation of different POCUS applications, including USG-PVA, in the pediatric intensive care unit[18-21] but a similar information in the NICUs is lacking. In particular, the degree of uptake USG-PVA in the NICU is largely unknown. Our nationwide survey is the first study assessing neonatologist's personal perspectives about USG-PVA and current implementation in the NICU. Our results indicate that neonatologists perceive USG-PVA as an indispensable or very useful aid in daily clinical practice and recognize the need for training during Pediatrics residency and Neonatology fellowship. However, our results indicate that USG-PVA is used infrequently in Spanish NICUs. As many as one third of the neonatologists in our survey have never used USG-PVA in their practice. Among those who use USG-PVA in their practice the number of procedures per year is quite low specially regarding placement of arterial lines and the use is even lower in the case of preterm infants.

Our results provide some insight into possible explanations behind the underuse of USG-PVA in the NICU. The first relates to training in vascular access. Most of the neonatologist who responded to our survey had not received formal training in POCUS or USG-PVA. In addition, an important proportion of neonatologists reported that residents and fellows are not trained in USG-PVA in their units. In this line, most neonatologists identify the lack of training as the most important limitation for implementation of USG-PVA above others such as lack of equipment, difficulty of the procedure or inherent risks. Those neonatologists working in high-complexity and large NICU used more frequently USG-PVA. However, in multivariate analysis only operator's previous training and age were independent predictors of the use of USG-PVA. This finding suggests that structured training is essential to acquire USG-PVA competence in neonates as these procedures are performed infrequently in clinical practice. For most neonatologists 10 to 50 procedures would be necessary to attain competence in USG-PVA. This number is similar to that recommended by some expert authorities. [22] According to our results, this may 
take years of clinical practice. Therefore, there is a need to implement training strategies to acquiring competence in USG-PVA more rapidly without compromising patient's safety. There are several recommendations on how USG-PVA training should be accomplished[22, 22-24]. Simulation is a powerful aid for training US guided procedures including vascular access.[25-27] Several vascular access models can be customized to recreate tiny vascular structures that are easy and cheap to build[18, 28]. In these models, the trainee gets familiarized with US vascular exploration and can repeatedly train dynamic needle tip guidance which is the essential skill for effective vascular access.

A second possible explanation for the scarce uptake of USG-PVA relates to the perception of risk and benefits of inserting CVCs and arterial lines in neonates. Most neonatologists considered that CVCs have a less favorable risk/benefit ratio compared to standard ECCs, specially in preterm infants.[29] In fact, the main indication for USG-CVC placement in our study was rescue from exhausted peripheral vein access. It seems that, USG-PVA is used mainly as a last resource for vascular access and perhaps performed late during evolution of NICU stay. In our opinion, this "high-risk" perception regarding CVC insertion in neonates may be an inertia from the past when CVCs were inserted by surgical cut-down in often extreme situations but current data in the US era do not support this conception. Recent research indicates that USG-PVA is safe in neonates. In particular, a growing number of reports have found that supraclavicular access to the BCV is feasible even in preterm infants with high insertion success rate and few mechanical complications and has been proposed as the optimal technique for CVC insertion in small infants and neonates[9, 10,30,31]. Furthermore, some data suggest that this technique may reduce catheter related blood stream infection compared to PICCs and other CVCs[32, 33]. However, the reported use of the BCV access in our survey was anecdotical. The most common location for central venous access was the FV. This is surprising as the FV is much smaller compared for instance to the IJV or BCV.[4, 31, 34] In addition, the FV may increase the risk of CRBSI or thrombosis. When asked to identify the largest vein amenable for PVA in neonates only one third of neonatologists mentioned the BCV and a similar number believed that the FV is the largest central vein for PVA. This indicate that most basic anatomical features of central veins might be ignored.

Beyond perceived risks, it is also possible that practitioners do not appreciate much benefit from the use of CVCs in neonates and this may hold true in most instances. ECCs are the most common devices for mid-term central venous access in neonates and they are excellent for routine care such as administration of parenteral nutrition or antibiotics. However, there are important limitations in the performance of these catheters such as low infusion rates, inability to infuse simultaneous medications, impossibility to draw blood or obtain hemodynamic monitoring as well as frequent catheter block and tip malposition. The sickest neonates and preterm infants who need high intensity care benefit from a large-bore safe and stable central catheter and competence in USG-CVC insertion is essential in these cases.

In our survey US was frequently used to check CVC tip position but still a majority of neonatologist perform a radiography for confirmation and expose the infant to ionized radiation. There have been several studies demonstrating accuracy of US in detecting central line tip and some have suggested that US should be the first-line modality to check central line tip location.[35, 36]

Regarding USG for arterial line placement, current use is even less frequent with most responders performing less than 5 procedures per year. In addition, most of the responders have never placed an USG arterial line in VLBWI. As expected, the most common reported indication for arterial cannulation was invasive arterial pressure monitoring. However, it seems that arterial lines are being placed infrequently and that most neonatologist rely on non-invasive blood pressure. This may not be surprising as technical difficulty for placing arterial lines in neonates is high and the risks derived from catheter related arterial ischemia are substantial. However, it has been demonstrated that non-invasive blood pressure is not reliable, especially in hypotensive preterm infants.[37] Hypotension is a strong predictor of mortality and adverse neurological outcome[38] and therefore, accurate and continuous measurement of arterial blood pressure is essential in the sickest infants with hemodynamically instability. USG facilitates not only cannulation, but also catheter selection based on actual arterial size a should be considered in hemodynamic compromised neonates when umbilical artery catheterization is not available. The reported preferred site for arterial line placement in our survey was the femoral artery. However, the use of USG radial artery catheterization may offer some advantages such a less risk of infection and occlusion-related ischemia given the presence of collateral circulation though the cubital artery. [39]

One interesting result in our study was the effect of operator's age in the reported use of USG-PVA. Age was an independent predictor of USG-PVA use. As expected, those practitioners with some experience in USG-PVA were younger and had less years of clinical practice compared to those who had never used this technique. Several studies have shown that senior practitioners may perform worse when switching to US and therefore may be reluctant to use USG-PVA in their practice ("old dog and new tricks" phenomenon)[20]. However, when considering only responses from neonatologist who currently use USG-PVA, we observed that older practitioners place more USG-

Page 10/16 
CVCs per year compared to the younger ones. This may suggest that acquiring confidence in these techniques in neonates is a slower process compared to children and adults. Taken together our results indicate that training in USG-PVA in Neonatology should begin early.

The main limitation of our study is the inherent risk of bias due to self-reporting of data and the relatively high non-response rate[40]. The willingness to respond the survey may be dependent on the personal interest on the topic of USG-PVA. It is possible that many neonatologists who are not interested about USG-PVA have not responded to the survey and that the actual use of UGS-PVA may be even lower than recorded. However, we have received responses from $62 \%$ of Spanish NICUs, including community-based hospitals as well as large referral centers so we think that our results are representative of current practice in our country. We think that our findings are an important first step to identify the needs and expectations regarding USG-PVA in the NICU. This is critical to elaborate coordinated strategies to implement training in USG-PVA and increase the uptake of this essential procedure in the next years.

In conclusion, despite most neonatologist perceive USG-PVA as very useful in daily practice, currently these techniques are underused. The lack of adequate training is perceived as the most important barrier for implementation of USG-PVA in the NICU. Our study highlights the need to develop and implement specific training programs in USG-PVA during residency and Neonatology fellowship.

\section{List Of Abbreviations}

BCV: brachiocephalic vein

CRBSI: catheter related blood stream infection

CVC: central venous catheter

ECC: epicutaneous-cava catheter

FV: femoral vein

IJV: internal jugular vein

NICU: neonatal intensive care unit

PVA: percutaneous vascular access

PICC: peripherally inserted central catheter

POCUS: point of care ultrasound

SENeo: Spanish Society of Neonatology

USG: ultrasound guided/guidance

US: ultrasound

VLBWI: very low birth weight infant ( $<1500$ grams)

WG-US: working group on ultrasound

\section{Declarations}

\section{ACKNOWLEDGMENTS}

To Lorena Rodeño-Fernández, coordinator of the WG-US for her support for preparation and diffusion of this work.

\section{FUNDING}

This study did not receive specific funding or grants.

\section{COMPETING INTERESTS}

The authors have no relevant financial or non-financial interests to disclose 
AVAILABILITY OF DATA AND MATERIAL

Data are available from the authors upon request.

\section{ATUHORS CONTRIBUTIONS}

Ignacio Oulego-Erroz conceived and designed the study, acquired data, analyzed data and drafted the manuscript.

Antonio Rodríguez-Núñez: designed the study and critically reviewed the manuscript for relevant intellectual content

Almudena Alonso-Ojembarrena, Victoria Aldecoa-Bilbao, Maria Carmen Bravo, Jon Montero-Gato, Rocío Mosqueda-Peña contributed to the study conception and design and critically reviewed the manuscript for relevant intellectual content

All authors gave their approval to the final version of the manuscript

\section{ETHICS APPROVAL}

The IRB reviewed and approved the study protocol (CEIC-León; ID: 20103).

\section{CONSENT TO PARTICIPATE}

The participants were informed of the study objectives and purposes. Participation was voluntary. The IRB waived the need for specific written informed consent for this survey study

\section{CONSENT FOR PUBLICATION}

Not applicable.

\section{References}

1. Souza Neto P, Grousson E, Duflo S et al (2014) Ultrasonographic anatomic variations of the major veins in paediatric patients. Br J Anaesth 112:879-884. https://doi.org/10.1093/bja/aet482

2. Lucas da Silva PS, Oliveira Iglesias SB, Leão FVF et al (2007) Procedural sedation for insertion of central venous catheters in children: comparison of midazolam/fentanyl with midazolam/ketamine. Paediatr Anaesth 17:358-363. https://doi.org/10.1111/j.1460-9592.2006.02099.x

3. Osmond E, Williams N (2021) Fifteen-minute consultation: Decision-making pathway for neonatal vascular access. Arch Dis Child Educ Pract Ed. https://doi.org/10.1136/archdischild-2020-320136

4. Tailounie M, Mcadams LA, Frost KC et al (2012) Dimension and overlap of femoral and neck blood vessels in neonates. Pediatr Crit Care Med 13:312-317. https://doi.org/10.1097/PCC.0b013e3182257a4c

5. Paterson RS, Chopra V, Brown E et al (2020) Selection and Insertion of Vascular Access Devices in Pediatrics: A Systematic Review. Pediatrics 145:S243-S268. https://doi.org/10.1542/peds.2019-3474H

6. Tomek S, Asch S (2013) Umbilical vein catheterization in the critical newborn: a review of anatomy and technique. EMS World 42:50-52

7. Pittiruti M, Ozkiraz et al (2013) J Vasc Access 2013;14(4):320-324. J Vasc Access 14:318-319. https://doi.org/10.5301/jva.5000158

8. Di Nardo M, Tomasello C, Pittiruti M et al (2011) Ultrasound-guided central venous cannulation in infants weighing less than 5 kilograms. J Vasc Access 12:321-324. https://doi.org/10.5301/JVA.2011.8309

9. Lausten-Thomsen U, Merchaoui Z, Dubois C et al (2017) Ultrasound-Guided Subclavian Vein Cannulation in Low Birth Weight Neonates. Pediatr Crit Care Med 18:172-175. https://doi.org/10.1097/PCC.0000000000001028

10. Oulego-Erroz I, Alonso-Quintela P, Terroba-Seara S et al (2018) Ultrasound-Guided Cannulation of the Brachiocephalic Vein in Neonates and Preterm Infants: A Prospective Observational Study. Am J Perinatol 35:503-508. https://doi.org/10.1055/s-00371608803

11. Oh C, Lee S, Seo J-M, Lee S-K (2016) Ultrasound guided percutaneous internal jugular vein access in neonatal intensive care unit patients. J Pediatr Surg 51:570-572. https://doi.org/10.1016/j.jpedsurg.2015.09.019

12. Singh Y, Tissot C, Fraga MV et al (2020) International evidence-based guidelines on Point of Care Ultrasound (POCUS) for critically ill neonates and children issued by the POCUS Working Group of the European Society of Paediatric and Neonatal Intensive Care

Page $12 / 16$ 
(ESPNIC). Crit Care 24:65. https://doi.org/10.1186/s13054-020-2787-9

13. Eysenbach G (2004) Improving the quality of Web surveys: the Checklist for Reporting Results of Internet E-Surveys (CHERRIES). J Med Internet Res 6:e34. https://doi.org/10.2196/jmir.6.3.e34

14. Sharma A, Minh Duc NT, Luu Lam Thang T et al (2021) A Consensus-Based Checklist for Reporting of Survey Studies (CROSS). J Gen Intern Med 36:3179-3187. https://doi.org/10.1007/s11606-021-06737-1

15. Ball HL (2019) Conducting Online Surveys. J Hum Lact 35:413-417. https://doi.org/10.1177/0890334419848734

16. Lamperti M, Bodenham AR, Pittiruti M et al (2012) International evidence-based recommendations on ultrasound-guided vascular access. Intensive Care Med 38:1105-1117. https://doi.org/10.1007/s00134-012-2597-x

17. Troianos CA, Hartman GS, Glas KE et al (2011) Guidelines for performing ultrasound guided vascular cannulation: recommendations of the American Society of Echocardiography and the Society of Cardiovascular Anesthesiologists. J Am Soc Echocardiogr 24:12911318. https://doi.org/10.1016/j.echo.2011.09.021

18. Wagner M, Hauser K, Cardona F et al (2018) Implementation and Evaluation of Training for Ultrasound-Guided Vascular Access to Small Vessels Using a Low-Cost Cadaver Model. Pediatr Crit Care Med 19:e611-e617. https://doi.org/10.1097/PCC.0000000000001721

19. Humblet MH, Singh Y, Tissot C et al (2020) Current Clinical Practice in Point-of-Care Ultrasound Use in the PICUs Across Europe. Pediatr Crit Care Med 21:e716-e722. https://doi.org/10.1097/PCC.0000000000002403

20. Oulego-Erroz I, González-Cortes R, García-Soler P et al (2018) Ultrasound-guided or landmark techniques for central venous catheter placement in critically ill children. Intensive Care Med 44:61-72. https://doi.org/10.1007/s00134-017-4985-8

21. Implementation of a pediatric critical care focused bedside ultrasound training program in a large academic PICU. - PubMed - NCBI. https://www.ncbi.nlm.nih.gov/pubmed/?

term=Implementation+of+a+Pediatric+Critical+Care+Focused+Bedside+Ultrasound+Training+Program+in+a+Large+Academic+PICU. Accessed 8 Jun 2019

22. Moureau N, Lamperti M, Kelly LJ et al (2013) Evidence-based consensus on the insertion of central venous access devices: definition of minimal requirements for training. Br J Anaesth 110:347-356. https://doi.org/10.1093/bja/aes499

23. Franco-Sadud R, Schnobrich D, Mathews BK et al (2019) Recommendations on the Use of Ultrasound Guidance for Central and Peripheral Vascular Access in Adults: A Position Statement of the Society of Hospital Medicine. J Hosp Med 14:E1-E22. https://doi.org/10.12788/jhm.3287

24. McLean AS (2011) International recommendations on competency in critical care ultrasound: pertinence to Australia and New Zealand. Crit Care Resusc 13:56-58

25. Oh EJ, Lee J-H, Kwon EJ, Min JJ (2020) Simulation-based training using a vessel phantom effectively improved first attempt success and dynamic needle-tip positioning ability for ultrasound-guided radial artery cannulation in real patients: An assessor-blinded randomized controlled study. PLoS ONE 15:e0234567. https://doi.org/10.1371/journal.pone.0234567

26. López-Álvarez JM, Pérez-Quevedo O, Naya-Esteban J et al (2021) Evaluation of Training in Pediatric Ultrasound-guided Vascular Cannulation Using a Model. J Med Ultrasound 29:171-175. https://doi.org/10.4103/JMU.JMU_109_20

27. Spencer TR, Bardin-Spencer AJ (2020) Pre- and post-review of a standardized ultrasound-guided central venous catheterization curriculum evaluating procedural skills acquisition and clinician confidence. J Vasc Access 21:440-448. https://doi.org/10.1177/1129729819882602

28. Pérez-Quevedo O, López-Álvarez JM, Limiñana-Cañal JM, Loro-Ferrer JF (2016) Design and application of model for training ultrasound-guided vascular cannulation in pediatric patients. Med Intensiva 40:364-370. https://doi.org/10.1016/j.medin.2015.11.005

29. Bahoush G, Salajegheh P, Anari AM et al (2021) A review of peripherally inserted central catheters and various types of vascular access in very small children and pediatric patients and their potential complications. J Med Life 14:298-309. https://doi.org/10.25122/jml-2020-0011

30. Aytekin C, Özyer U, Harman A, Boyvat F (2015) Ultrasound-guided brachiocephalic vein catheterization in infants weighing less than five kilograms. J Vasc Access 16:512-514. https://doi.org/10.5301/jva.5000385

31. Uzumcugil F (2021) Pre-procedural ultrasound-guided evaluation of left internal jugular vein and brachiocephalic vein: Experience on infants <1 year. J Vasc Access 22:492-495. https://doi.org/10.1177/1129729820925692

32. Oulego-Erroz I, Fernández-García A, Álvarez-Juan B et al (2020) Ultrasound-guided supraclavicular cannulation of the brachiocephalic vein may reduce central line-associated bloodstream infection in preterm infants. Eur J Pediatr 1-9. https://doi.org/10.1007/s00431-

Page $13 / 16$ 
020-03663-y

33. Habas F, Baleine J, Milési C et al (2018) Supraclavicular catheterization of the brachiocephalic vein: a way to prevent or reduce catheter maintenance-related complications in children. Eur J Pediatr 177:451-459. https://doi.org/10.1007/s00431-017-3082-x

34. Barone G, D'Andrea V, Vento G, Pittiruti M (2019) A Systematic Ultrasound Evaluation of the Diameter of Deep Veins in the Newborn: Results and Implications for Clinical Practice. Neonatology 115:335-340. https://doi.org/10.1159/000496848

35. Sharma D, Farahbakhsh N, Tabatabaii SA (2019) Role of ultrasound for central catheter tip localization in neonates: a review of the current evidence. J Matern Fetal Neonatal Med 32:2429-2437. https://doi.org/10.1080/14767058.2018.1437135

36. Fraga MV, Stoller JZ, Glau CL et al (2019) Seeing Is Believing: Ultrasound in Pediatric Procedural Performance. https://doi.org/10.1542/peds.2019-1401. Pediatrics 144:

37. König K, Casalaz DM, Burke EJ, Watkins A (2012) Accuracy of non-invasive blood pressure monitoring in very preterm infants. Intensive Care Med 38:670-676. https://doi.org/10.1007/s00134-012-2499-y

38. Faust K, Härtel C, Preuß M et al (2015) Short-term outcome of very-low-birthweight infants with arterial hypotension in the first $24+\ldots . . h$ of life. Arch Dis Child Fetal Neonatal Ed 100:F388-392. https://doi.org/10.1136/archdischild-2014-306483

39. Shah S, Kaul A, Mishra S, Pawale S (2021) Clinical experience of use of percutaneous peripheral arterial cannulation in sick neonates in a developing country. BMC Pediatr 21:484. https://doi.org/10.1186/s12887-021-02943-2

40. Berman DM, Tan LLJ, Cheng TL (2015) Surveys and Response Rates. Pediatr Rev 36:364-366. https://doi.org/10.1542/pir.36-8-364

\section{Figures}




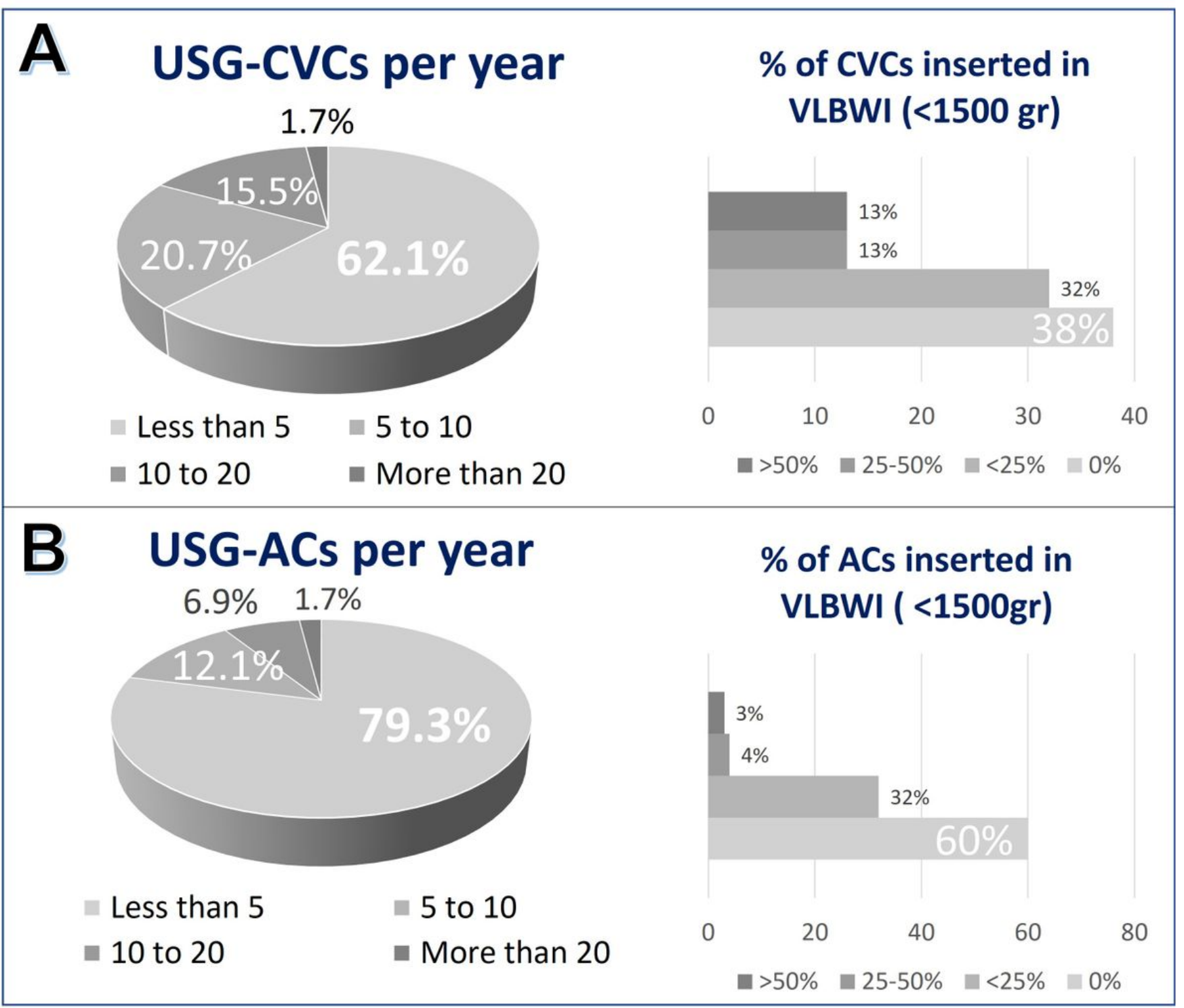

Figure 1

Number of ultrasound-guided percutaneous vascular access procedure per year

Foot:

Panel A, Number of ultrasound-guided central venous catheter (USG-CVC) insertions per year and percentage performed in very low birth weight infants

Panel A, Number of ultrasound-guided central arterial catheter (USG-AC) insertions per year and percentage performed in very low birth weight infants 


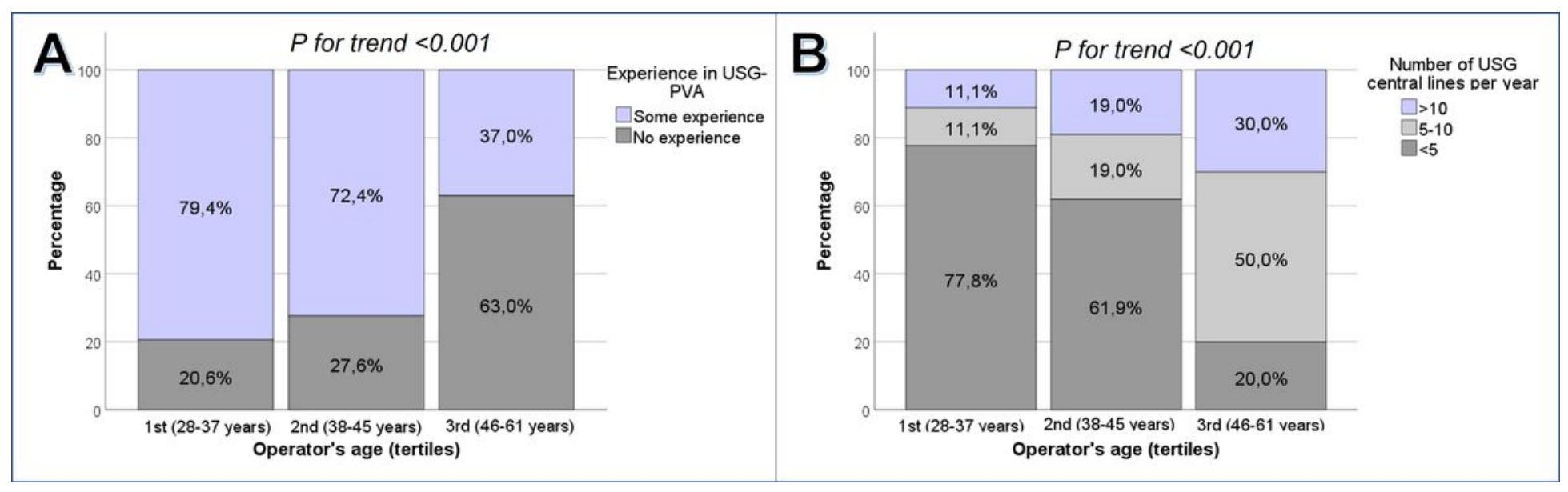

Figure 2

Relationship between operator's age and experience in ultrasound guided percutaneous vascular access procedures

Foot:

Panel A: Clinical experience in ultrasound guided percutaneous vascular access (USG-PVA) procedures according to operator's age tertiles. $P$ for lineal trend in $\chi$-square test

Panel B: Number of ultrasound-guided central venous catheter procedures (USG-CVC) according to operator's age tertiles $(n=116)$. $P$ for lineal trend in $X$-square test

\section{Supplementary Files}

This is a list of supplementary files associated with this preprint. Click to download.

- APPENDIX1EJP.docx

- SupplementaryTables1EJP.docx

- Supplementarytables2EJP.docx 